\title{
Non-destructive testing application for diagnosis of long-running civil and industrial facilities under special climatic conditions
}

\author{
Bandurin Mikhail A. \\ Doctor of Technics, associate professor \\ FSBEI HE Platov South-Russian State Polytechnic \\ University (NPI) \\ Novocherkassk, Rostov region, Russia \\ e-mail:chepura@mail.ru \\ Vanzha Vladimir V. \\ Candidate of Technics, associate professor \\ FSBEI HE Kuban State Agrarian University named after \\ I.T. Trubilin \\ Krasnodar, Krasnodar krai, Russia \\ e-mail: Vanzha_vv@mail.ru
}

\author{
Volosukhin Victor A. \\ Doctor of Technics, professor \\ FSBEI HE Platov South-Russian State Polytechnic \\ University (NPI) \\ Novocherkassk, Rostov region, Russia \\ e-mail: ngma_str_meh@mail.ru \\ Mikheyev Alexander V. \\ Candidate of Technics, associate professor \\ FSBEI HE Platov South-Russian State Polytechnic \\ University (NPI) \\ Novocherkassk, Rostov region, Russia \\ e-mail:avmih@mail.ru
}

\author{
Volosukhin Yakov V. \\ graduate student \\ FSBEI HE Platov South-Russian State Polytechnic University (NPI) \\ Novocherkassk, Rostov region, Russia \\ e-mail: yashas@rambler.ru
}

\begin{abstract}
The given article considers the necessity of implementation of new systems of technical diagnostics for a long-term exploitation of civil and industrial facilities under special climatic conditions. Currently, more than $80 \%$ of civil and industrial facilities in southern Russia have worked out their rated life. At the same time, there is a simultaneous increase in the load on aging facilities so that the absence of the necessary qualified personnel and technical repair base, will inevitably lead to an increase in the number of accidents caused by exploitation causes. The general purpose of conducting technical diagnostics is to identify the degree of physical deterioration, the deterioration causes, the actual efficiency of the elements and plans to ensure their various exploitation parameters, as well as a description of the technical condition. The most dangerous one is the risk of accidents and defects on vulnerable sites that include many civil and industrial facilities.
\end{abstract}

Keywords-Non-destructive testing, technical diagnostics, civil and industrial facilities, climatic conditions.

\section{INTRODUCTION}

Untimely identified and not eliminated defects and damages often turn into serious structural violations of civil and industrial facilities and the inability to use the entire facility. Therefore, it is important to correctly and timely assess the elements state of civil and industrial facilities and to anticipate their damage repair at an early stage of development. Currently existing methods to determine the serviceability of such facilities are visual and use destructive impact methods, the accuracy of which is insufficient. Thereby, there is a necessity to search for new modern methods for reliability measurement of civil and industrial facilities to be able to perform their timely repairs and to prevent further destruction.

At present, there are no methods for a technical state quantitative assessment and methods of exploitation monitoring of civil and industrial facilities using nondestructive testing devices [1]

Technical state of civil and industrial facilities has been determined with the application of non-destructive testing devices in combination with computational investigation using the finite element analysis of the technical state of the facility's structure on the basis of the following factors:

- the geometric dimensions of civil and industrial facilities and their sections;

- the presence of cracks, their dimensions, as well as spalling and damages;

- the quantitative parameters of deflections and deformations of structures; 
The problem of facilities safety is becoming more and more relevant every year. The primary measure for preventing accidental destruction of the facilities is the assessment of the technical condition of both individual structural elements and the entire structure as a whole.

Currently, in practice, there are various terms to assess the technical condition of water conveyance facilities, some of which are represented in the standard technical documentation [5]. According to the instructions on the procedure for determining the criteria of safety and assessment of various facilities state on industries, plants and organizations supervised by the Federal Mining and Industrial Inspectorate of Russia, there are two safety criteria levels - from the 1st to the 2 nd level. On the basis of safety criteria, the conditions of facilities are determined and classified according to the types:

Reliable or efficient state of facilities is the state when the facility meets all the regulatory and design requirements under the basic loads combination, the values of the facilities state monitored indicators do not exceed (not less than) the corresponding safety criteria of the 1 st level. The facility could be used without developing any measures to increase the safety of its exploitation.

Satisfactory, partly non-operable state - a state when the value of at least one monitored indicator has become more (less) than the corresponding safety criteria of the 1st level, but the values of the monitored indicators of the facilities state do not exceed (not less than) the corresponding safety criteria of the 2nd level. The facility is under the influence of loads and impacts that do not exceed the planned values of the basic loads combination.

At the same time, civil and industrial facilities could be exploited provided that the necessary measures are developed and implemented within a certain time. These measures are developed on the basis of specific indicators' analysis on the factors that could create an emergency situation and contain the necessary measures to neutralize the effect of such factors [6].

Pre-accidental, ultimate limit state of civil and industrial facilities is a state when the facility is damaged or defective so that it could not be exploited under the basic loads combination because of the threat of an accident and / or the facility is under the special loads combination exceeding the allowable values with the threat of an accident, and / or there are signs of a progressive development of destructive processes that irreversibly lead to an accident.

The prevailing accidental defects are the complete destruction, the formation of defects that disrupt the normal facility exploitation; butt joints failure, as well as destruction of the bearing area and the interlock part. Dangerous defects causing the deterioration of operating ability in the structural elements are the formed cracks, the sizes of which exceed the limit values, the delamination of the protective layer of concrete, the corrosion of concrete reinforcement in the form of efflorescence and rusty stains [7].

It may be concluded that the butt joints failure of prefabricated elements, the wall breaks and breaches in different zones, cracks, shifting and subsidence of the 
elements relative to each other lead to the abnormal exploitation of the facility. The solution of these problems should be based on the compulsory registration of reliability requirements for the design, construction and exploitation.

The main indicator in assessing the state of a construction is the possibility of its further exploitation, and all other conditions, one way or another, determine this possibility. The physical deterioration of civil and industrial facilities could be approximated by some parameters dynamically changing in time and assessed depending on many factors:

- current and major repairs of structures and facilities;

- technical exploitation;

- the level of impact of dynamic loads on foundations;

- the impact of man-made, seismic and climatic processes;

- changes in the geotechnical foundations state;

- aging of the material of civil and industrial facilities under the atmospheric influences.

The existing methods of building constructions' surveying [8] are aimed at assessing the overall suitability of facilities' load-bearing constructions for further exploitation. When conducting surveys of civil facilities, a number of questions emerged regarding the nature of the damages and defects detection, as well as the forecasting of technical state for a certain period of time. Therefore, there is a necessity to create a methodology for surveying and forecasting the technical state of civil facilities.

The monitoring is carried out regarding the current regulations on design, manufacturing and exploitation specifics. Also it outlines the main requirements for the process of assessment of the facilities technical state using modern non-destructive testing instruments.

The assessment results of the technical state are the source data for compiling a report on the state of the surveyed sites.

When assessing the technical state of civil and industrial facilities, a non-destructive testing devices have been used with the application of ultrasonic and shock pulse methods. To determine the geometric characteristics of the civil and industrial facilities defects and damages, the OCO-2 georadar has been used, and to determine the actual strength of the concrete in the locations of defects and damages, the electronic concrete strength meter IPS-MG4,01 has been applied [9] (figure 1).

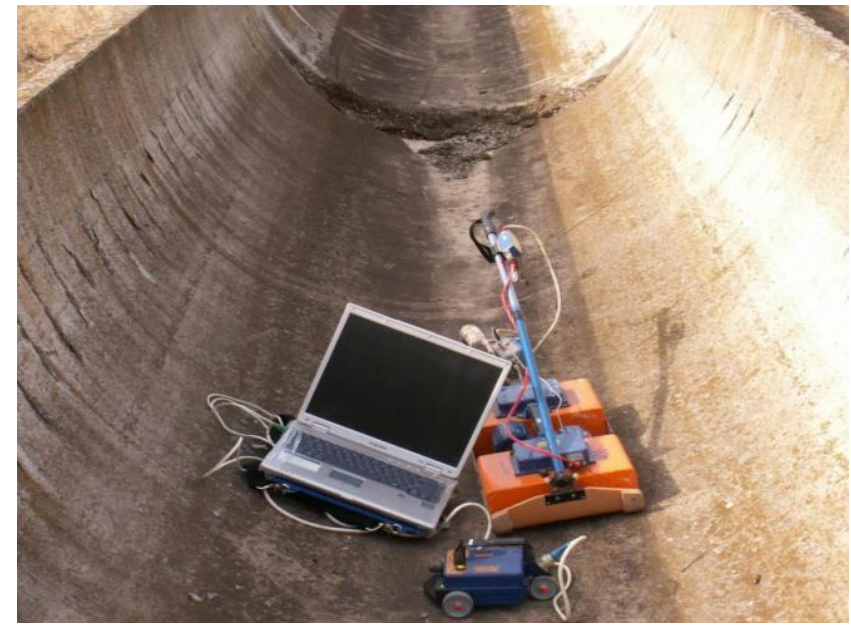

Fig. 1. Georadar OCO-2.

The monitoring system includes profiles surveying. To establish the actual strength of various building constructions included into the exploitation complex by the shock pulse method, the electronic strength meter IPS-MG4,01 has been used. The test points have been attached to georadar surveys to determine the strength of each construction at characteristic points of the profiles [9] (figure 2).

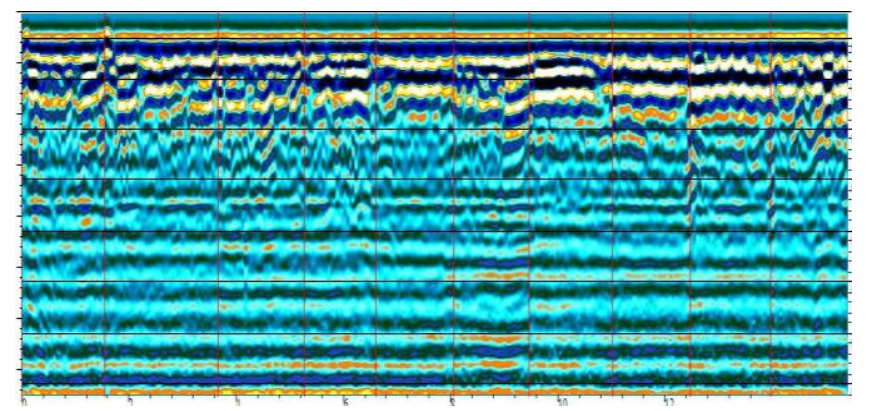

Fig. 2. The GPR surveying profile fragment of the reinforced concrete beam.

In the course of field testing, defects and damage have been found in various civil and industrial facilities. As a result, on the example of the reinforced concrete beams it has been established that the destruction in the lower part of the beam occurs in most cases because the beam in this place is in the most unfavorable exploitation conditions. The presence of these damages after a long term exploitation of the beam is due to the imperfect production technology of the building elements, as well as imperfection of construction and installation works [10]. Figure 3 shows a radarogram, where the regions with intense darkening correspond to areas with a higher energy of the reflected signal, in comparison with the light regions. The region with a low energy of the reflected signal corresponds to a more homogeneous area than the region with a high energy of the reflected signal. It could be seen that in the region of $0-3 \mathrm{~m}$ and 6-9 $\mathrm{m}$ the inhomogeneity of the area reaches a depth of $40 \mathrm{~cm}$. 


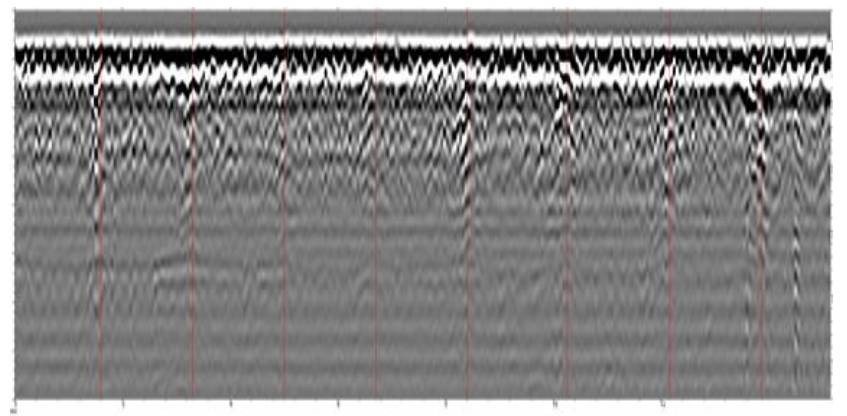

Fig. 3. The GPR surveying profiles fragments of a reinforced concrete beam section with various defects and damages.

The parameters subjected to non-destructive testing in the concrete are strength, the protective layer size, humidity, frost resistance, moisture-proofness and a number of others. The reinforcement tension and the vibration magnitude during the concrete consolidation are also controlled in the production of concrete goods. But the main controlled parameter for the concrete is the compressive strength [11].

The durability of the reinforced concrete structure is significantly influenced by the value of the protective layer of concrete and the presence of the defects like shells, pores, cracks, etc. on it. The protective layer protects the concrete reinforcement from moisture, oxygen, corrosive substances and gases. The reinforcing bars, having a small protective layer or significant defects in it, are the first to corrode. (figure $4)$.

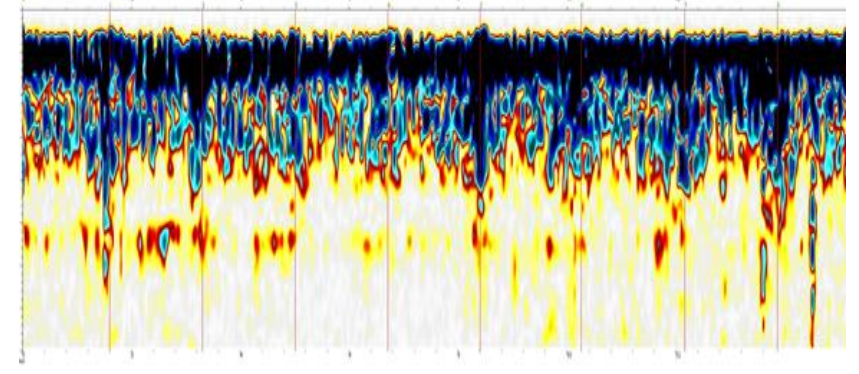

Fig. 4. The GPR surveying profile fragment of a concrete element with highlighted pinholes of a figure caption.

Figure 5 shows a GPR surveying profile fragment along the width of a bridge crossing pier with a highlighted concrete reinforcement and a water contact zone. The reflections from the web reinforcing bars are distinguished in the upper part of the section of the radargram. Below is a layer, with reflections from numerous local objects.

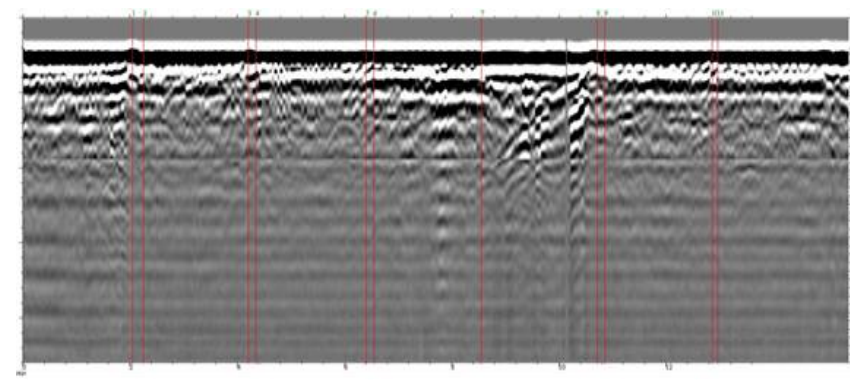

a)

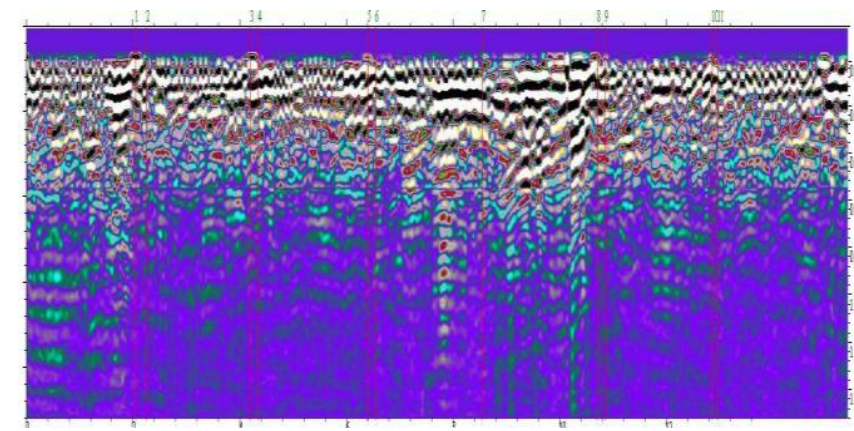

b)

Fig. 5. The GPR surveying profile fragment of a concrete element with highlighted pinholes and a water contact zone: a) untreated ;b) processed.

When surveying the bridge crossing, it has been established that the piers have characteristic destructions of the protective concrete layer, the exposure of the concrete fabric in places of contact with water $\left(\mathrm{R}_{\mathrm{fs}}=35,4 \mathrm{MPa}\right.$ concrete class B 30), along the upper side $\left(\mathrm{R}_{\mathrm{fs}}=43.2 \mathrm{MPa}\right.$ concrete class $\mathrm{B}$ $35)$. The piers surveying showed the concrete delamination and its corrosion in the bearing area on the foundation plate $\left(\mathrm{R}_{\mathrm{fs}}=39.4 \mathrm{MPa}\right.$ concrete class B 30).

Steel members of the bridge crossings have been surveyed for the metal thickness by the ultrasonic echo-pulse thickness gauge A1209.

When choosing the ultrasonic echo-pulse thickness gauge, measurements have been made coming not only from the facilities' metal thickness range, but the degree of curvature and roughness of the gate surfaces, the ultrasonic absorption and scattering in the metal, and other conditions have also been taken into account.

Later, solid models of the load-bearing elements of various civil and industrial facilities have been built and the stressstrain state of the reinforced concrete load-bearing elements under various combinations of loads has been considered as a result of the experiment.

To establish the adequacy of the solid model of the stressstrain state has been the goal of the formulation of the numeric calculation of the load-bearing elements of various civil and industrial facilities without the defects formation. The diagrams displacement comparisons of the load-bearing elements, both vertically, horizontally along and across the load-bearing elements, revealed slight internal changes. Horizontal displacements along the load-bearing elements 
show insignificant displacements of the bearing areas of the reinforced concrete beams, and horizontal displacements of the load-bearing elements show displacements of the edge piers and the reinforced concrete beams beared against them.

At the second stage, the load-bearing elements of the bridge crossing with the defects and damages formation have been modeled, namely the formation destruction and decompaction zones of the reinforced concrete on the pier. The most characteristic and dangerous defect is the loss of the load-bearing capacity of one the bridge crossing piers, namely the edge one - as the most exposed to external influences and experiencing the greatest von Mises equivalent [12].

The diagram of vertical displacements shows a critical change in the position of the pier and the beams beared against it due to a reduction in its load-bearing capacity in view of the defect formation. There is a critical displacement of the pier head, resulting in a loss of stability of the beams beared against it. The given results indicate the load-bearing capacity loss of the vertical element - the pier.

Horizontal displacements along the load-bearing elements show insignificant displacements of the reinforced concrete beams bearing areas, and horizontal displacements across the load-bearing elements show a critical displacement of the edge pier that pulls the beared against reinforced concrete beams with it.

When comparing the von Mises equivalent and the displacements, the greatest stresses occur along the vertical side of the bridge crossing load-bearing elements, namely on the head of the edge pier and the horizontal beams beared against it. These results indicate the occurrence of critical stresses in the bearing areas that are twice as great as in the other bridge crossing piers that in its turn leads to the destruction of the considered elements and the loss of the bearing capacity of the entire facility.

Further modeling of the defects on the pier in the form of pinholes' formation and decompactions of the reinforced concrete with the loss of the load-bearing capacity to half of its area has been made. Dimensions of the defect diameter begin from $50 \mathrm{~mm}$ to $100 \mathrm{~mm}$. During the modeling, an intensive danger areas has been established, the pier destruction occurs starting from a diameter of $100 \mathrm{~mm}$ [13].

As a result of the numeric experiments the defect and damage formation zones on the load-bearing elements of the bridge crossings through water-conducting channels that may have similar characteristic damages have been allocated. It allows regulating the process of laying the GPR surveying profile and determining the points where it is necessary to assess the concrete strength during field surveys. In this regard, modeling of the defects produced on the pier in the form of pinholes and decompactions of the reinforced concrete with the diameter from $50 \mathrm{~mm}$ to $100 \mathrm{~mm}[14,15]$ have been made. The intense danger area has been established, starting with $100 \mathrm{~mm}$ diameter pinholes and decompactions of the reinforced concrete.

\section{CONCLUSION}

Thus, the use of non-destructive testing devices in the survey of civil and industrial facilities allows one to obtain a prompt objective assessment of their technical state without additional damage, namely: to establish the fact of the presence of various defects and damages, to determine their geometric parameters (width, depth and length) as well as the actual concrete strength in the locations of defects. When using this approach, it becomes possible to justify the defects and damages parameters that could not be established by visual inspection.

Processing with the help of modern computer technologies and generalizing makes it possible to increase, quickly and without significant expenditures, information scope for stressed and strained state and, above all, to work out wellfounded plans and competent designs of further explorations that are to be conducted at the modern scientific and technical level.

Currently the problem of assessing the residual life of water conveyance facilities, even after the special loads impact, is one of the most urgent problems in the field of ensuring safe exploitation of water conveyance facilities requiring their permission to predict the amount of this resource in time until exhaustion of its use values. The problem of determining the residual resource could be solved with different severity of its formulation.

1. The national standard of Russia allows formulating the basic requirements for the permanent monitoring of civil and industrial facilities.

2. Qualitative permanent monitoring of civil and industrial facilities allows assessing the change in the stress-strain state under various combinations of loads.

3. Analysis of the unsatisfactory state of individual civil and industrial facilities in the south of the Russian Federation indicates a high number of facilities with unsatisfactory and dangerous levels of security.

\section{References}

[1] V.I. Olgarenko, G.V. Olgarenko, I.V. Olgarenko, "Integrated assessment of the technical level of the irrigation and drainage systems", Melioration and water management, vol. 6, pp. 8-11, 2013.

[2] Zh. Shi, R. Wang, M.X. Huang, D. Landgraf, "Detection of coastal saline land uses with multi-temporal landsat images in Shangyu City", China Environmental Management, vol. 30(1), pp. 142-150, 2002.

[3] Al.Md. Mahbubul, C. Wagner, "The Relative Importance of Monetary and Non-Monetary Drivers for Information and Communication Technology Acceptance in Rural Agri-business", Information Technology for Development, 2016, vol. 2, pp. 1-18.

[4] I.F. Yurchenko, "Automatization of water distribution control for irrigation", International Journal of Advanced and Applied Sciences, vol. 4(2), pp.72-77, 2017.

[5] F.K. Abdrazakov, N.F. Ryzhko, S.N. Ryzhko, S.A. Horin, S.V. Botov, "Electricity consumption decrease at pump stations during watering by multi-support sprinkling units", Journal of Fundamental and Applied Sciences, vol. 10, pp. 1464-1481, 2018.

[6] B.P. Chesnokov, O.V. Naumova, V.A. Strelnikov, F.K. Abdrazakov, B.A. Tronin, "Polyethylene production from granules using high voltage", International Journal of Applied Engineering Research, vol. 11 , pp. 2140-2144, 2016. 
[7] O. Degtyareva, G. Degtyarev, I. Togo, V. Terleev, A. Nikonorov, Yu. Volkova, "Analysis of stress-strain state rainfall runoff control system buttress dam”, Procedia Engineering, vol. 165, pp. 1619-1628, 2016.

[8] G Bonifazi, L Cutaia, P Massacci, I Roselli, "Monitoring of abandoned quarries by remote sensing and in situ surveying", Ecological Modelling, vol. 2-3, pp. 213-218, 2003.

[9] V.A. Volosukhin, M.A. Bandurin "Monitoring, diagnostics and residual life of bearing structures of prefabricated water-lifting low-pressure shield dams", Vestnik of the Don State Agrarian University, vol. 41(18), pp. 61-71, 2015.

[10] M.A. Bandurin, "Features of technical diagnostics of long-running water supply facilities", Engineering journal of Don, vol. 20(2), pp. 693-696, 2012.

[11] O.G. Degtyareva, D.A. Dac'o, G.V. Degtyarev, A.D. Gumbarov, "Design in cae system of low-head weir tiled foundation sinking",
Proceedings of the Kuban State Agrarian University, vol. 64, pp. 221226, 2017.

[12] I.F. Yurchenko, "Information systems of managing water economy ameliorative complex", Bulletin of Russian Agricultural Science, vol. 1, pp. 12-15, 2016.

[13] A. Downes, A. Elfick, D. Salter, "Finite element simulations of tipenhanced raman and fluorescence spectroscopy", Journal of Physical Chemistry B: Biophysical Chemistry, Biomaterials, Liquids, and Soft Matter, vol. 110(13), pp. 6692-6698, 2006.

[14] V.V. Kozharinov, V.N. Sushentsov, N.I. Mukhurov, P P Mardilovich, "Nondestructive tests of dielectric coating thickness and quality based on frequency characteristics of electric discharge", Russian Journal of Nondestructive Testing, vol. 36(9), pp. 681-684, 2000.

[15] J.R. Brence, D.E. Brown, "Data mining from eddy current nondestructive tests", Computers \& Industrial Engineering, vol. 43(4), pp 821-839, 2002. 